\title{
Monitoring fish passes using infrared beaming: a case study in an Iberian river
}

\author{
By J. M. Santos ${ }^{1}$, P. J. Pinheiro ${ }^{1}$, M. T. Ferreira ${ }^{1}$ and J. Bochechas ${ }^{2}$ \\ ${ }^{1}$ Centro de Estudos Florestais, Instituto Superior de Agronomia, Universidade Técnica de Lisboa, Lisboa, Portugal; ${ }^{2}$ Divisão de \\ Pesca em Águas Interiores, Direç̧ão-Geral dos Recursos Florestais, Lisboa, Portugal
}

\begin{abstract}
Summary
An application of a new automated fish counting device - the Riverwatcher System (RW) - was used to monitor upstream fish movements in a pool-and-weir fish pass in the River Zêzere, Portugal, for 141 days from June 2002 to May 2003. Fish populations were also collected downstream using multimesh gillnets (5 different mesh sizes ranging from $30 \mathrm{~mm}$ to $85 \mathrm{~mm}$ knot to knot; ratio between mesh sizes of about 1.30) and electrofishing for comparison with fish records produced by the RW. More than 3000 individual Iberian nase Chondrostoma polylepis ascended the fish pass and moved through the RW during the study period. However, only $18 \%$ of the records produced by the RW contained silhouettes similar to fish; no individual smaller than $15 \mathrm{~cm}$ TL was recorded by the counter. Most seasonal movements (73.9\%) occurred in spring and were associated with reproduction. Displacements seemed to occur independently of time of day. Water temperature (range: $12-22^{\circ} \mathrm{C}$ ) was the only significant environmental variable $(\mathrm{P}<0.01)$ influencing upstream movements of this species. Further development of hardware and software will be necessary to improve performance of the counter, particularly in Mediterranean rivers, where more turbid waters and a greater proportion of small-size species are present.
\end{abstract}

\section{Introduction}

Different monitoring techniques have been used around the world to monitor and evaluate the performance of fish passes. However, prohibitive money and time constraints have limited the goals of such studies. Trapping (Stuart and Berghuis, 2002) can cause injury or stress to the fish and is limited by the impossibility of collecting continuous, real-time data. Visual observation and video recording (Santos et al., 2002, 2005) are very time-consuming, and are dependent upon location and number of viewing stations and the cost of the equipment involved. Mark-recapture studies (Knaepkens et al., 2005) are dependent upon the location and timing of capture and recapture sites, are often used for populations rather than communities, and are designed for the analysis of intensive small-scale investigations. Radio telemetry (Lucas et al., 2000) is quite expensive in terms of both equipment and manpower. Moreover, the behaviour and performance of the fish may be disturbed due to handling, anaesthesia and implantation of the transmitter. Although Passive Integrated Transponder (PIT) technology (Castro-Santos et al., 1996) has proven to be a relatively inexpensive method for detecting large numbers of tagged fish in fish passes, the fish must pass through a confined area $\left(<1000 \mathrm{~cm}^{2}\right)$ in order to be detected by the readers, and this is not always feasible, especially for larger fish.
More recently, a new automated fish counting device - the Riverwatcher System (RW) - was developed by VAKI Aquaculture Systems Ltd. in Iceland. The RW has been used quite successfully in Iceland, Scandinavia, Ireland, Scotland and North America to monitor the migration of salmon and trout. However, most of the documented evaluation studies are published only in reports or other grey literature (Brown and Newton, 2002; Porcella et al., 2004). On the other hand, its performance remains unknown in more turbid waters, such as Mediterranean-type rivers, and with cyprinid species, whose movements have received comparatively less attention. The main goals of the present investigation were therefore to: (1) test the functionality of the system in more turbid waters with a high level of debris; (2) study characteristics of the upstream movement of cyprinid fish populations; (3) describe the periodicity of displacements; (4) assess the influence of key environmental factors on the ascent of fish populations; and (5) evaluate the performance of the RW using the above goals as an assessment tool.

\section{Study area}

The River Zêzere in Central Portugal has a catchment area of approximately $5050 \mathrm{~km}^{2}$ and flows for over $220 \mathrm{~km}$ from its source in the Serra da Estrela to the River Tagus (Fig. 1). The river is regulated by three large dams, two small hydropower plants (SHPs) and several small weirs, which are used for hydroelectric energy and domestic water supplies. The study was conducted at the pool-and-weir fish pass at the Janeiro de Cima SHP, $72 \mathrm{~km}$ upstream from the Cabril Dam and $88 \mathrm{~km}$ downstream from the Manteigas SHP. The river is characterized by deep pools and also has well-defined riffle sections. Stream-bed materials are mainly dominated by boulders and rubble, with silting taking place in pool habitats. The availability of cover for fish is generally high, mainly in the form of logs, roots and beds of aquatic macrophytes.

The fish pass is $63-\mathrm{m}$ long and $1.5-\mathrm{m}$ wide on a $10 \%$ slope, with 26 baffles creating 25 pools that are each $1.9-3.5 \mathrm{~m}$ long. Each baffle has a $0.30-\mathrm{m}$ wide surface notch and a $0.2 \times 0.2-\mathrm{m}$ submerged orifice flow on alternate sides creating a sinusoidal flow path. The head difference between the pools is $0.30 \mathrm{~m}$. The flow in the fish pass is mainly dependent on the headwater level. A coarse screen at the upstream exit prevented large debris from entering the pass. Based on hydraulic criteria, the effectiveness of the fish pass was estimated to be highly suitable for the target species (Santos et al., 2006). 
Fig. 1. Study area and sampling location in River Zêzere. Black triangles indicate small hydropower plants Arrow indicates pool-and-weir fish pass with the Riverwatcher System (RW)

\section{Material and methods}

A Vaki RW was installed in the fish pass to monitor fish passage through the facility over the course of one year. The RW uses infrared light diodes to count passing fish. Data is relayed to an on-site computer, where it is stored in a database (control unit). The counter itself is a rectangular shaped unit (scanner unit), which is completely submerged within one of the pools in the fish ladder. Fish are directed through the counter opening, which is lined with infraredlight-emitting diodes. When a fish swims through the counter and breaks the plane of light beams, the fish is scanned and a resulting silhouette image is sent to the on-site computer. Other recorded information includes the speed at which the fish was travelling, the direction of the movement (upstream vs downstream) and the timing of passage events. The RW also measures the height of fish passing through it and then estimates the length using a length/height ratio. It was placed at the entrance to the fifth pool from the top of the pass, and operated whenever flow in the facility was greater than $0.24 \mathrm{~m}^{3} \mathrm{~s}^{-1}$. The counter was first tested and calibrated by comparing migrant counts with fish trapped just upstream in a standard migrant trap (fyke net). Fish passing through the scanner unit into the trap were counted visually during 8-h periods (trials) using a flash-board that was attached between the upstream exit of the scanner and the trap opening. It was thus possible to check whether visually counted fish were simultaneously being registered by the RW. Four trials were conducted over 6 days prior to the monitoring programme. The mean length/height ratio of fish captured in the trap - 267 Iberian nase Chondrostoma polylepis and 4 Iberian chub Squalius pyrenaicus - and measured out of the water was 4.8 and 5.4 with a $93 \%$ and $88 \%$ correlation, respectively. These were consequently the calibration default values for both species. The ratios were updated seasonally as more information was collected. Distance between scanners was set at $39 \mathrm{~cm}$. Typical maintenance included clearing debris build-up on the counter, downloading data from the database, and resetting the system.

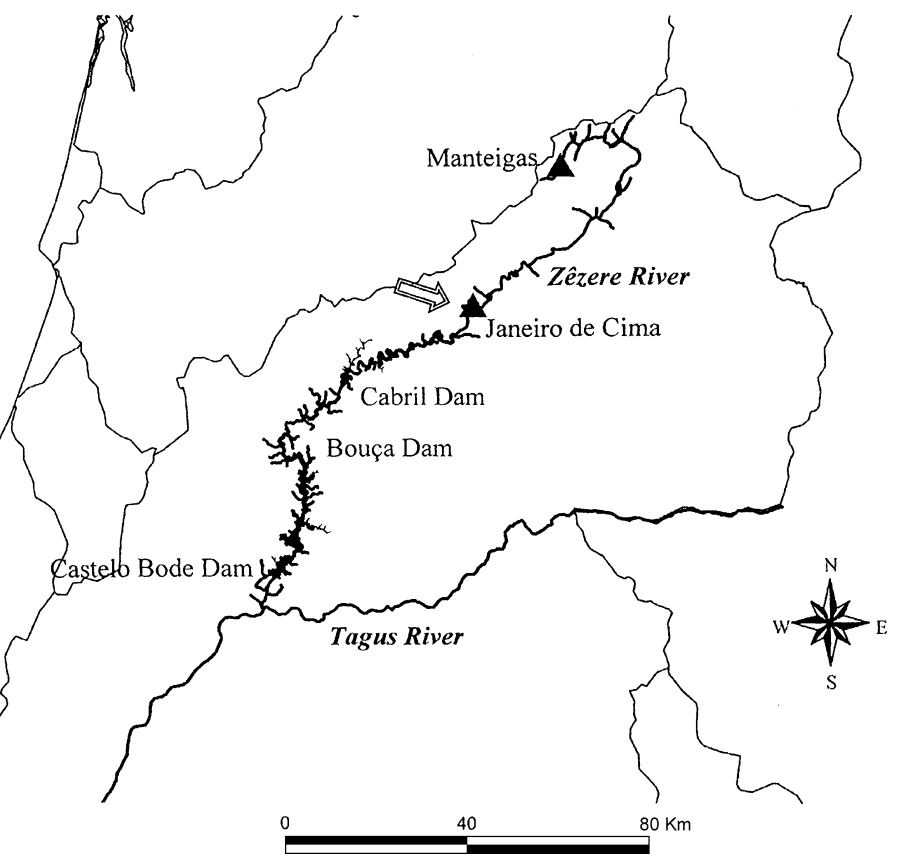

Periodic sampling of the entire channel below the weir was carried out in order to validate the fish records produced by the RW. Two $30 \mathrm{~m}$-long $\times 2.5 \mathrm{~m}$-high multimesh gillnets composed of 5 different mesh sizes $(30,39,50,65$ and $85 \mathrm{~mm}$ from knot to knot; ratio between mesh sizes of about 1.30 ) were set up before dusk in a large pool (c. $70 \times 40 \mathrm{~m}$ ) immediately below the fish pass at the surface and on the bottom, and lifted after dawn. Fish from each catch were sorted by species, counted and measured. In the shallowflowing area further downstream (c. $650 \mathrm{~m}^{2}$ ), fish were sampled using electrofishing during daylight by means of a generator-powered DC electrofisher (Electracatch International, SAREL model WFC7-HV) with $400 \mathrm{~V}$ and a constant 3 -A average output to a $40-\mathrm{cm}$ stainless steel anode system. One person operated the electrofishing equipment while two others, one on either side, netted the fish. The sampling crew moved upstream in a zigzag pattern to ensure full coverage of all habitats. In both cases sampling was performed monthly and expressed in terms of CPUE (catch per unit effort - gill nets: number of fish per $75 \mathrm{~m}^{2}$ of gill nets per night; electrofishing: catch per $30 \mathrm{~min}$ ).

After analysing the data collected by the RW, the number of ascending individuals was graphed for fish species on a monthly basis. A histogram was constructed by calculating the relative frequency of hourly passages. A non-parametric Mann-Whitney $U$-test (Zar, 1996) was performed to detect significant differences between the diurnal (06.00-18.00 hours) and nocturnal (18.00-06.00 hours) number of individuals per day. A stepwise multiple regression was used to test the effect of environmental variables on the number of fish passing through the RW. Fish-pass discharge, head-and tailwater level, water temperature, and precipitation were used as independent variables. Fish-pass discharge was obtained using a PDCR 830 pressure transducer and a Xytec 7100 ultrasonic velocity meter. Data on head-and tailwater levels were recorded daily by telescope levelling. Precipitation records were obtained from the nearest weather station. A daily mean was used for independent variables. The Durbin-Watson statistic (D) (Durbin and Watson, 1951) was used to test for first-order 
autocorrelation in the residuals of each regression. The test was only carried out for the period when the ascent of fish was at its greatest -i.e. from March 1 to May 31. Before regression, the fish numbers were transformed as $\log _{10}(x+1)$.

\section{Results}

A total of 3056 individuals ascended the fish pass and moved through the RW fish counter over a period of 141 days between June 2002 and May 2003 (Fig. 2). Only 18\% of the total records $(\mathrm{n}=550)$ contained silhouettes similar to fish. In addition, $8 \%(n=244)$ of the total records contained a software error in which passage events were registered but no silhouette was recorded at all. Minimum fish length recorded by the counter was $15 \mathrm{~cm}$. The RW system did not produce accurate silhouettes; we were therefore not able to differentiate between possibly different species of fish (Fig. 3). However, sampling downstream from the weir revealed a fish assemblage composition that was restricted to two species: Iberian nase, and Iberian chub. These species presented distinct spatial distribution and size-structures in both studied habitats (Fig. 4). Accordingly, Iberian nase were captured significantly more abundantly in the gill nets than Iberian chub $(U=8.5$, $\mathrm{P}<0.05)$. Mean CPUE $( \pm 1 \mathrm{SD})$ was $46.6 \pm 33.1$ and $6.6 \pm 12.3$ ind. $75 \mathrm{~m}^{2}$ net $^{-1}$ night $^{-1}$, respectively. Significant differences in size-structure were also found between the two species (Kolmogorov-Smirnov test, $Z=1.66, \mathrm{P}<0.01$ ): nase length varied from 15.2 to $25.0 \mathrm{~cm}$, with a mean length $( \pm 1 \mathrm{SD})$ of $17.9 \pm 2.7 \mathrm{~cm}$, whereas chub length varied from 5.7 to $13.7 \mathrm{~cm}$, with a mean length of $8.1 \pm 1.9 \mathrm{~cm}$. On the other hand, chub were significantly more abundant than nase in shallow-flowing waters sampled by electrofishing $(U=7.0$, $\mathrm{P}<0.05)$. Mean CPUE was $97.1 \pm 65.0$ and $38 \pm 61.2$ ind.

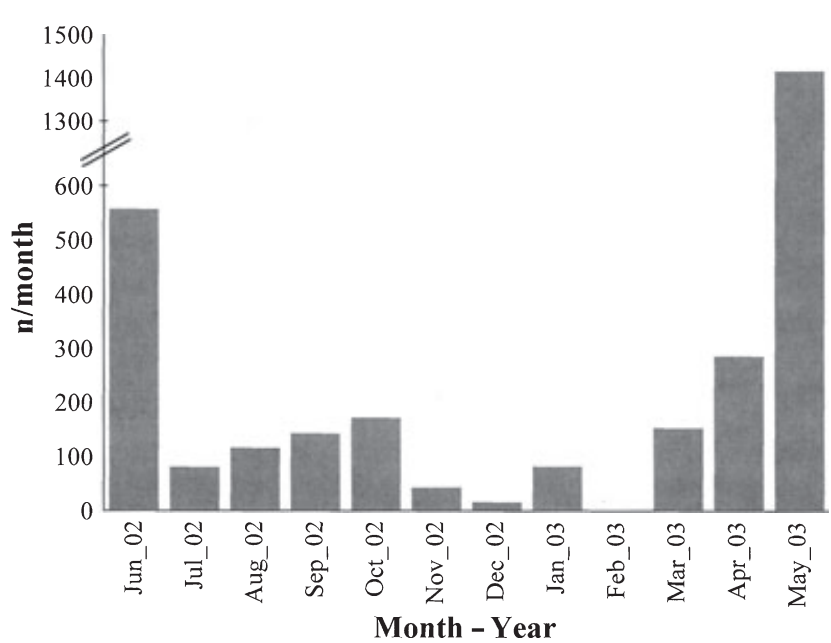

Fig. 2. Number of ascending fish per month (n/month) registered by the Riverwatcher System (RW) at Janeiro de Cima pool-and-weir fish pass in 141 days from June 2002 to May 2003

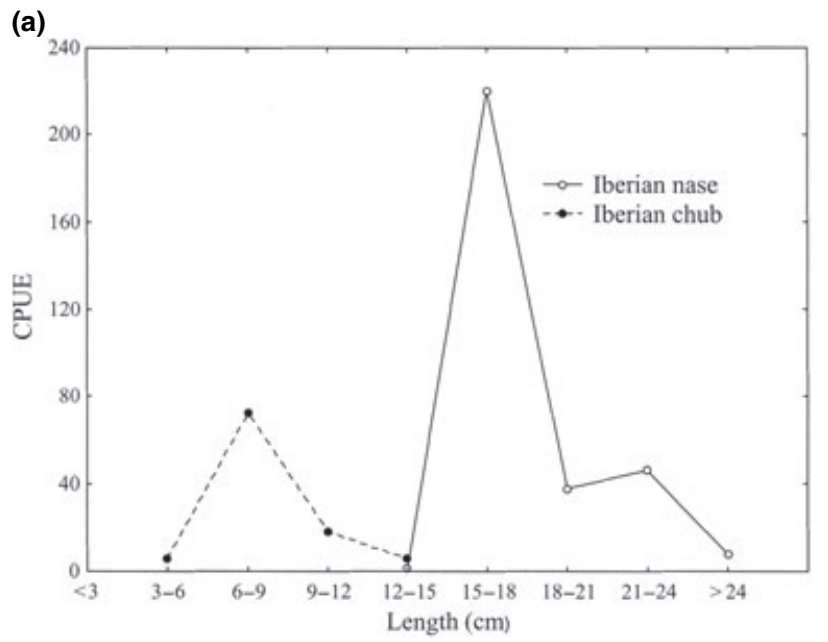

(b)

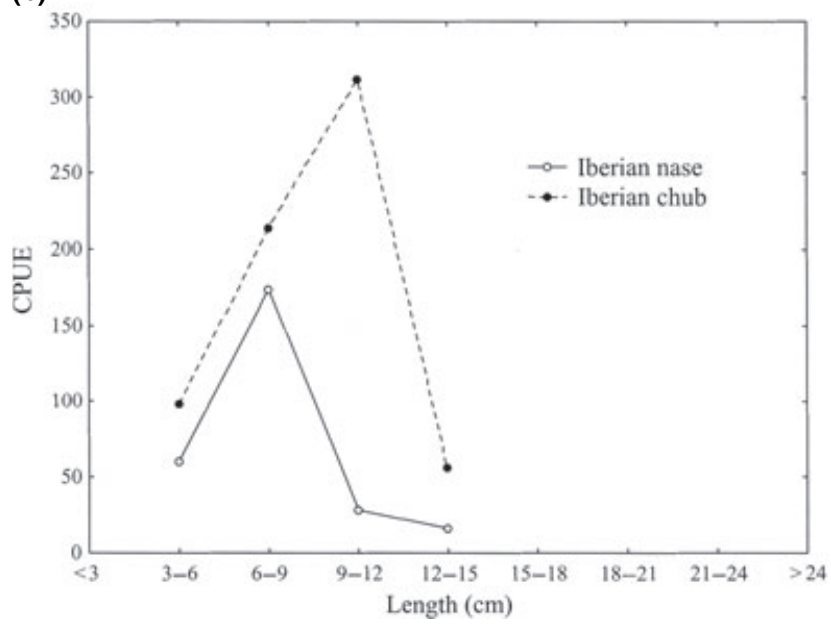

Fig. 4. CPUE of fish-length distribution assessed downstream from the weir at the small hydropower plant of Janeiro de Cima by (a) gill nets (number of fish per $75 \mathrm{~m}^{2}$ night $^{-1}$ ) and (b) electrofishing (number of fish per $30 \mathrm{~min}$.)

$30 \mathrm{~min}^{-1}$, respectively. Differences in size-structure between species were also significant (Kolmogorov-Smirnov test, $Z=3.02, \mathrm{P}<0.01)$. Total length of the chub varied from 4.0 to $14.9 \mathrm{~cm}$ (mean: $9.0 \pm 2.3 \mathrm{~cm}$ ), whereas nase length ranged from 4.5 to $14.5 \mathrm{~cm}$ (mean: $7.3 \pm 1.9 \mathrm{~cm}$ ). Altogether, the Iberian nase was the only species that presented individuals greater than $15 \mathrm{~cm} \mathrm{TL}$, which was the minimum length recorded by the RW. Based on estimated fish lengths produced by the counter, fish migrating upstream were therefore most likely to be Iberian nase. Nevertheless, where particular species were concerned, there may still have been sources of identification-related bias in the analysis of the records - an issue that will be addressed in the discussion.

Upstream movements of Iberian nase occurred mainly in spring $(73.9 \%)$, with a peak passage in May $2003(46.4 \%$ of

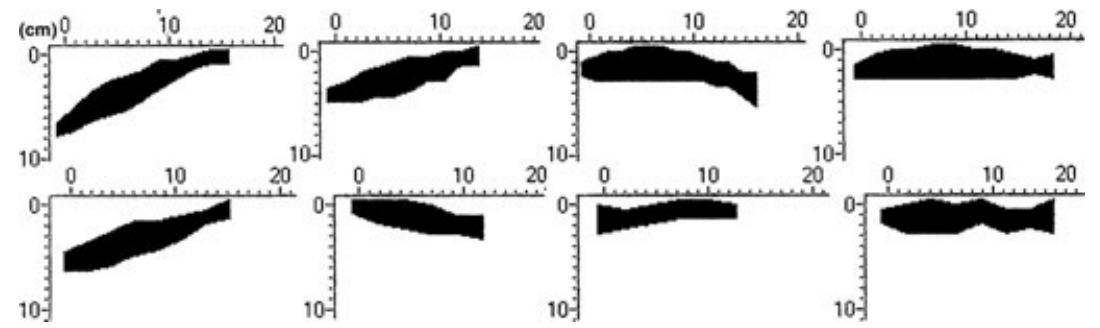

Fig. 3. Silhouette examples recorded by the Riverwatcher System (RW) at Janeiro de Cima pool-and-weir fish pass from June 2002 to May 2003 Note the lack of defining characteristics, including dorsal and anal fins 
total observations). Nase seemed to use the fish pass independently of time of day, as no significant preferences between diurnal and nocturnal periods were found in their upstream movements (Mann-Whitney $U$-test, d.f. $=141, \mathrm{P}>0.05$ ) (Fig. 5). Mean number of individuals per day was 12.9 and 10.5 , respectively. Multiple regression analysis indicated that water temperature (range: $12-22^{\circ} \mathrm{C}$ ) was the only significant environmental variable influencing the ascent of Iberian nase ( $F$-test, $\left.R^{2}=0.38, \mathrm{P}<0.01\right)$, with a pronounced activity in temperatures between $15^{\circ} \mathrm{C}$ and $17^{\circ} \mathrm{C}$. There was no significant autocorrelation $(D=1.53, \alpha=0.05)$ in the residuals of the regression.

\section{Discussion}

Of the 3056 upstream movement records collected by the $\mathrm{RW}$, only $18 \%$ contained silhouettes similar to fish, whereas $8 \%$ contained no image at all. It is possible that an excess of drifting debris and turbulence could have been overwhelming the system and causing unclear images or even an absence of image records. Also, water clarity could have been a problem for the entire time the RW was operational, due to high turbidity and algal blooms, particularly in the summer. In Mediterranean streams, where floods occur irregularly in winter and spring, the scouring of accumulated sediment and debris usually causes relatively high concentrations of suspended solids throughout the wet season (Gasith and Resh, 1999). Although debris problems were minimized in the fish pass, this software error was still a common occurrence. However, our results do not agree with those obtained on the Thorsa River, Iceland (VAKI-DNG Ltd, 2000), where it was found that the RW functioned suitably to at least a secchi depth of $10.2 \mathrm{~cm}$, which corresponds to highly turbid waters. While there is no direct correlation between secchi depth and NTU, it is clear that future research should clarify, in NTUs, the turbidity at which the system no longer reliably counts fish.

Regular sampling throughout the year using gill nets and electrofishing revealed a site-specific fish assemblage dominated by two species: Iberian nase, and Iberian chub. We assumed that the full record set collected by the RW corresponded to individual Iberian nase, and give three reasons to support this. Firstly, catch data within the large pool immediately downstream from the pass revealed that all individual nase were greater than $15 \mathrm{~cm}$ TL, which was the minimum length recorded by the counter. On the other hand, no individual chub larger than $15 \mathrm{~cm}$ TL was collected by

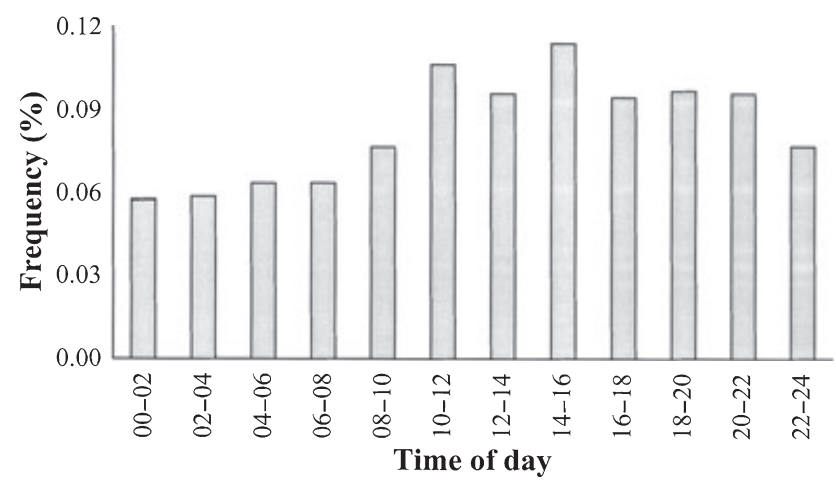

Fig. 5. Frequency of hourly passages (time of day) of upstream nase movements recorded by the Riverwatcher System (RW) at Janeiro de Cima pool-and-weir fish pass, June 2002 to May 2003 either by gill nets or electrofishing. We do not exclude the possibility that a few larger $(>15 \mathrm{~cm}$ TL) individuals of this species may have been present in the study area and have been counted by the RW, but this does seem quite unlikely, since this small-sized species rarely exceeds $15 \mathrm{~cm}$ TL in rivers (Carmona et al., 1999). However, this may be problematic in other Mediterranean rivers, where traditionally a higher number of species is present and their size ranges overlap (Vila-Gispert et al., 2002; Santos et al., 2004), because the RW may not yield a sharp enough silhouette to distinguish between them. It is clear that further development of the hardware and software has to be pursued in order to improve performance of the RW, particularly in Mediterranean rivers. Secondly, during the calibration procedure prior to this study, $98.5 \%$ of the individuals captured in the trap were Iberian nase, whereas only $1.5 \%$ were Iberian chub (of these, none were over $15 \mathrm{~cm}$ TL). Finally, throughout the study period Iberian nase were often observed ascending the fish pass. Unlike the chub, which often adopts a pool-dwelling behaviour (Carmona and Doadrio, 2000), this species makes upstream migrations in spring to find appropriate spawning habitats, and may travel tens of kilometres in the process (Lucas et al., 2000; Santos et al., 2002).

Most upstream Iberian nase movements ( $>70 \%$ ) occurred in spring (April-June), with a maximum in May ( $46 \%$ of total observations). It is likely that these numbers are low, since nase may have moved upstream during the periods when the counter was non-functional. A similar pattern was observed in other Iberian rivers (Lobón-Cerviá, 1982; Santos et al., 2005), and is generally described as reproductive migrations (Rodriguez-Ruiz and Granado-Lorencio, 1992). The diel activity of nase movements through the fish pass displayed differences from the patterns described in the literature. Like most of the other cyprinids, the nase - a species with more sustained activity in the evening and night (Prignon et al., 1998; Santos et al., 2002, 2005) - performed their movements continuously over $24 \mathrm{~h}$-periods. It is possible that the frequent high water turbidity means there is no survival premium for night-time migrations, when survival would be expected to be at its highest (Jonsson, 1991).

Stepwise regression revealed water temperature to be the main factor affecting upstream nase movements. This result supports some studies (Rodriguez-Ruiz and Granado-Lorencio, 1992; Santos et al., 2002), but not others (Santos et al., 2005), in which fish-pass discharge seemed to be the major physical factor associated with migration. It is likely that a hierarchy of environmental factors may trigger the same behaviour in different rivers (Jonsson, 1991).

Like any new technology, the RW experienced some limitations and problems during the study period. The counter did not seem to be accurate for smaller fish (i.e. $<15 \mathrm{~cm}$ TL), and it is therefore unlikely that juveniles and small-sized migrating species could be counted with this device. At the same time the 'Winari' database software suffered from errors, which prevented us from obtaining a complete and accurate silhouette dataset. Nevertheless, we were able to collect valuable information on fish passage through the pool-andweir fish pass. Further development of the hardware and software will be necessary to improve the performance of the $\mathrm{RW}$, especially in Mediterranean rivers where particular water quality conditions, such as higher turbid waters and debris load, and a high proportion of small-sized endemic species, are present (Almaça, 1995; Godinho et al., 1997). The benefits of this system could be immense if the device were to function 
properly under the environmental conditions found in these types of rivers.

\section{Acknowledgements}

The authors would like to thank António Albuquerque and Luis Lopes for their assistance with the fieldwork, and Mr Eric Hafner and his staff, who gave advice and practical help and allowed us to conduct the study at their facility. We also would like to thank Richard Rogers and two anonymous referees for their constructive and helpful review of an earlier draft. This research was supported financially by the Direcção-Geral dos Recursos Florestais (National Forest and Wildlife Service).

\section{References}

Almaça, C., 1995: Freshwater fish and their conservation in Portugal Biol. Conserv. 72, 125-127.

Brown, M. R.; Newton, J. M., 2002: Monitoring adult Chinook salmon, rainbow trout, and steelhead in Battle Creek, California, from March through October 2001. U.S. Fish and Wildlife Service, Red Bluff Fish and Wildlife Office, Red Bluff, California, USFWS Report, pp. 54.

Carmona, J. A.; Doadrio, I., 2000: Threatened fishes of the world: Leuciscus carolitertii Doadrio, 1988 (Cyprinidae). Environ. Biol. Fish. 57, 96.

Carmona, J. A.; Doadrio, I.; Márquez, A. L.; Real, R.; Hugueny, B. Vargas, J. M., 1999: Distribution patterns of indigenous freshwater fishes in the Tagus River basin, Spain. Environ. Biol. Fish. 54, 371-387.

Castro-Santos, T.; Haro, A.; Walk, S., 1996: A passive integrated transponder (PIT) tag system for monitoring fishways. Fish. Res. 28, 253-261.

Durbin, J.; Watson, G. S., 1951: Testing for serial correlation in least squares regression II. Biometrika 38, 159-178.

Gasith, A.; Resh, V. H., 1999: Streams in Mediterranean climate regions: abiotic influences and biotic responses to predictable seasonal events. Annu. Rev. Ecol. Syst. 30, 51-81.

Godinho, F. N.; Ferreira, M. T.; Cortes, R. V., 1997: Composition and spatial organisation of fish assemblages in the lower Guadiana basin, southern Iberia. Ecol. Freshw. Fish. 6, 134-143.

Jonsson, N., 1991: Influence of water flow, water temperature and light on fish migration in rivers. Nordic J. Freshw. Res. 66, 20-35.

Knaepkens, G.; Baekelandt, K.; Eens, M., 2005: Assessment of the movement behaviour of the bullhead (Cottus gobio), an endangered European freshwater fish. Anim. Biol. 55, 219-226.
Lobón-Cerviá, J., 1982: Population analysis of the Iberian nose (Chondrostoma polylepis Stein, 1865) in the Jarama River. Vie Milieu 32, 139-148.

Lucas, M. C.; Mercer, T.; Peirson, G.; Frear, P. A., 2000: Seasonal movements of coarse fish in lowland rivers and their relevance to fisheries management. In: Management and ecology of river fisheries. I. G. Cowx (Ed.). Fishing New Books, Oxford, pp. 87100

Porcella, L.; Nishijima, J.; Salsbery, D., 2004: Alamitos fish ladder monitoring report 2003-2004. Project No. 00742011, Santa Clara Valley Water District, Guadalupe Watershed Division. pp. 11.

Prignon, C.; Micha, J. C.; Gillet, A., 1998: Biological and environmental characteristics of fish passage at the Tailfer dam on the Meuse River, Belgium. In: Fish migration and fish bypasses. M. Jungwirth, S. Schmutz and S. Weiss (Eds), Fishing New Books, Cambridge, pp. 69-84.

Rodriguez-Ruiz, A.; Granado-Lorencio, C., 1992: Spawning period and migration of three species of cyprinids in a stream with Mediterranean regimen (SW Spain). J. Fish Biol. 41, 545-556.

Santos, J. M.; Ferreira, M. T.; Godinho, F. N.; Bochechas, J., 2002 Performance of fish lift recently built at the Touvedo Dam on the Lima River, Portugal. J. Appl. Ichthyol. 18, 118-123.

Santos, J. M.; Godinho, F. N.; Ferreira, M. T., 2004: Microhabitat use by Iberian nase Chondrostoma polylepis and Iberian chub Squalius carolitertii in three small streams, north-west Portugal. Ecol. Freshw. Fish. 13, 223-230.

Santos, J. M.; Ferreira, M. T.; Godinho, F. N.; Bochechas, J., 2005 Efficacy of a nature-like bypass channel in a Portuguese lowland river. J. Appl. Ichthyol. 21, 381-388.

Santos, J. M.; Ferreira, M. T.; Pinheiro, A. N.; Bochechas, J., 2006 Effects of small hydropower plants on fish assemblages in medium-sized streams in Central and Northern Portugal. Aquat. Conserv. 16, 373-388.

Stuart, I. G.; Berghuis, A. P., 2002: Upstream passage through a vertical-slot fishway in an Australian subtropical river. Fisheries Manage. Ecol. 9, 111-122.

VAKI-DNG Ltd, 2000: Letter from B. Traustason (VAKI-DNG Ltd.) to $\mathrm{T}$. McCarthy (Water Management Technologies) regarding turbidity levels. VAKI-DNG Ltd, December 13, 2000.

Vila-Gispert, A.; García-Berthou, E.; Moreno-Amich, R., 2002: Fish zonation in a Mediterranean stream: effects of human disturbances. Aquat. Sci. 64, 163-170.

Zar, J. H., 1996: Biostatistical analysis. Prentice Hall International, Inc., NJ, USA, pp. 662.

Author's address: José Maria Santos, Departamento de Engenharia Florestal, Instituto Superior de Agronomia, Tapada da Ajuda, P-1349-017 Lisboa, Portugal. E-mail: jmsantos@isa.utl.pt 
Copyright of Journal of Applied Ichthyology is the property of Blackwell Publishing Limited and its content may not be copied or emailed to multiple sites or posted to a listserv without the copyright holder's express written permission. However, users may print, download, or email articles for individual use. 